\title{
Simulations for the development of a ground motion model for induced seismicity in the Groningen gas field, The Netherlands
}

\author{
B. Edwards ${ }^{1}$ (D) B. Zurek ${ }^{2} \cdot$ E. van Dedem ${ }^{3} \cdot$ P. J. Stafford ${ }^{4} \cdot$ S. Oates ${ }^{3} \cdot$ J. van Elk $^{5}$. \\ B. deMartin ${ }^{2}$. J. J. Bommer ${ }^{4}$
}

Received: 2 April 2018 / Accepted: 17 September 2018 / Published online: 25 September 2018

(c) The Author(s) 2018

\begin{abstract}
We present simulations performed for the development of a ground motion model for induced earthquakes in the Groningen gas field. The largest recorded event, with M3.5, occurred in 2012 and, more recently, a M3.4 event in 2018 led to recorded ground accelerations exceeding $0.1 \mathrm{~g}$. As part of an extensive hazard and risk study, it has been necessary to predict ground motions for scenario earthquakes up to $\mathbf{M} 7$. In order to achieve this, while accounting for the unique local geology, a range of simulations have been performed using both stochastic and full-waveform finite-difference simulations. Due to frequency limitations and lack of empirical calibration of the latter approach, input simulations for the ground motion model used in the hazard and risk analyses have been performed with a finite-fault stochastic method. However, in parallel, extensive studies using the finite-difference simulations have guided inputs and modelling considerations for these simulations. Three approaches are used: (1) the finite-fault stochastic method, (2) elastic point- and (3) finite-source 3D finite-difference simulations. We present a summary of the methods and their synthesis, including both amplitudes and durations within the context of the hazard and risk model. A unique form of wave-propagation with strong lateral focusing and defocusing is evident in both peak amplitudes and durations. The results clearly demonstrate the need for a locally derived ground motion model and the potential for reduction in aleatory variability in moving toward a path-specific fully non-ergodic model.
\end{abstract}

Keywords Earthquake ground motion $\cdot$ Duration $\cdot$ Stochastic simulation $\cdot$ Finite-difference simulation $\cdot$ Seismic hazard

Electronic supplementary material The online version of this article (https://doi.org/10.1007/s1051 8-018-0479-5) contains supplementary material, which is available to authorized users.

B. Edwards

ben.edwards@liverpool.ac.uk

Extended author information available on the last page of the article 


\section{Introduction}

The Groningen gas field, located in the north-east of the Netherlands, is the largest known source of natural gas in Europe and has been in production since 1963. From 1991 to 2012 compaction-induced earthquakes increased in frequency and were followed by the largest recorded event to date, a M3.5 (Dost et al. 2018) occurring in Huizinge on 16th August, 2012. Production controls have led to a recent reduction in seismicity, however, a M3.4 event on 8th January 2018 led to the highest recorded ground motions, at $0.11 \mathrm{~g}$. The earthquakes have led to intense public and political debate. In an effort to mitigate the effects of these earthquakes the field operator, Nederlandse Aardolie Maatschappij B.V. (NAM), commissioned a comprehensive data collection, monitoring and hazard and risk study (Bommer et al. 2017a; van Elk et al. 2017) that has been ongoing since 2013. The results of this study have been submitted at regular intervals to the regulator in order to inform decisions made regarding production levels. The models have also informed the earthquake loading in the revised Dutch seismic design code for the region (NEN-NPR).

A fundamental component of the hazard and risk models produced as part of the production plan and NEN-NPR seismic design code is the Groningen ground motion model (GMM, Bommer et al. 2016). Ground motions recorded on the dense high-resolution dual surface-borehole seismic network (Dost et al. 2017) have highly region specific characteristics due to the complex geology (Kraaijpoel and Dost 2013), and characteristic reservoir-bound seismicity (Spetzler and Dost 2017). A local empirical ground motion prediction equation (GMPE, Dost et al. 2004) developed using data from a neighbouring gas field (Roswinkel, $50 \mathrm{~km}$ from Groningen) was an initial candidate model for providing input motions to the hazard and risk analyses. However, the GMPE was shown by Bourne et al. (2015) to significantly over-predict both peak ground acceleration and velocity (PGA and PGV). This was interpreted as being mainly due to the fact that in Groningen the high-velocity Zechstein salt layer lies above the gas reservoir, whereas in the Roswinkel field the gas reservoir is above the Zechstein (Kraaijpoel and Dost 2013). The motivation for undertaking finite-difference simulations, which reflect the geological controls on wave propagation, is to gain insights into this strong local variability.

The inability of the Dost et al. (2004) GMPE to predict the motions recorded from events in the Groningen gas field prompted the development of the Groningen GMM. Five successive versions (V1-5) of the model have used increasingly sophisticated simulations to capture the epistemic uncertainty of predicting how ruptures, of broadly unknown character, may behave at larger magnitude. The Groningen GMM has evolved from an adjusted European empirical GMPE, to a GMM logic-tree based on finite-fault stochastic simulations. These simulations have been guided by full-waveform finite-difference simulations and account for source and path characteristics based on locally recorded events, along with transitions of material properties as ruptures penetrate the Carboniferous. Non-linear site response analysis through the upper $\sim 800 \mathrm{~m}$ of overburden then brings the simulations from the reference rock horizon to the surface (Bahrampouri et al. 2018; Bommer et al. 2017a, b; Kruiver et al. 2017; Noorlandt et al. 2018; Rodriguez-Marek et al. 2017; Stafford et al. 2017).

\section{Simulation techniques and their application to Groningen}

Earthquake simulations have the potential to fill the empirical data-gap that restricts earthquake ground motion analyses: specifically, motions at short distance from large ruptures, both being relative to the seismicity of the study region. In addition, they facilitate the derivation of 
high resolution models which can capture local effects due to wave propagation through heterogeneous local geology. Several simulation methodologies have been developed over the past decade and can be broadly split into full waveform simulations (using Green's functions, e.g. finite difference or spectral element methods) and stochastic simulations (using random phase and simplified seismological models of the Earth's response). Both methods can use kinematic or dynamic sources based on properties of the fault. Full-waveform simulations are typically computationally limited to relatively low frequencies (e.g. $\mathrm{f}<5 \mathrm{~Hz}$ ) and are dependent on the accuracy and resolution of the velocity models (which reduces for increasing frequency). On the other hand, stochastic approaches aim to provide waveforms with suitable spectral characteristics - with no consideration of signal phase (considered acceptable for calculating pseudo spectral acceleration, PSA, used in engineering applications). Stochastic methods rely on simplified physical models calibrated using empirical data from the study region but are susceptible to inversion non-uniqueness.

Two approaches are considered in this work: (1) fully stochastic and (2) kinematic fullwaveform finite-difference simulations (with both deterministic and stochastic sources). Both methods have been initially developed for point source models and subsequently extended to finite-fault ruptures.

\subsection{Full-waveform finite-difference modelling}

The particle displacement $\boldsymbol{u}\left(\boldsymbol{r}, t ; \boldsymbol{s}, t_{0}\right)$ due to a point shear dislocation of arbitrary orientation, $\boldsymbol{s}$, at time $t_{0}$, calculated at a given receiver position $\boldsymbol{r}$ at time $t$, is defined as the convolution of the moment tensor $\widehat{\mathbf{M}}$, accounting for the source mechanism, and the gradient of the Green's function, $\boldsymbol{G}$ (Aki and Richards 1980):

$$
\boldsymbol{u}\left(\boldsymbol{r}, t ; \boldsymbol{s}, t_{0}\right)=\widehat{\mathbf{M}}\left(t ; \boldsymbol{s}, t_{0}\right) * \nabla \boldsymbol{G}\left(\boldsymbol{r}, t ; \boldsymbol{s}, t_{0}\right),
$$

The expression is valid for a point-source approximation, such that the fault dimension is negligible with respect to the wavelengths that dominate the displacement field. We assume a homogeneous source rupture process, such that all components of the moment tensor have the same time dependence, defined by the source wavelet $w(t)$. We can therefore decouple the time dependence of the moment tensor from the source strength and orientation such that:

$$
\widehat{\mathbf{M}}=M_{0} m_{i j} w(t) .
$$

Here $M_{0}=\mu \bar{u} A=10^{1.5 \mathrm{M}+9.05}$ (in SI units) is the scalar seismic moment defined as the product of rigidity $\mu$, average slip $\bar{u}$ and fault area $A$. The moment tensor density, $m_{i j}$, represents the nine possible force couples and $\mathbf{M}$ is the moment magnitude. For a double-couple source, the six independent components of the symmetric moment tensor can be expressed as functions of the focal angles strike $\varphi \operatorname{dip} \delta$ and rake $\lambda$. Once the Green's function gradients have been computed for a given source location, three-component displacements for different focal mechanisms can be obtained. For the computation of the Green's function gradients an elastic finite-difference scheme is employed (Mulder and Plessix 2002). For the source wavelet, a source-time-function is chosen based on a causal slip model (Brune 1970; Madariaga 2007) which is fixed at simulation time:

$$
w(t)=\omega_{c}^{2} t e^{-\omega_{c} t} H(t),
$$


where $\omega_{c}$ is the corner frequency of the source wavelet's Fourier spectrum, and $\mathrm{H}(\mathrm{t})$ is the Heaviside step function. Waveform data are computed for each source location, over a grid of three component receivers at a predefined datum corresponding to the reference rock horizon (the base of the Upper North Sea formation). The elastic model used for the simulations (e.g. Fig. 1), containing P- and S-wave velocities and density, has been constructed for the Groningen gas field, and is constrained by depth imaging velocities, geological horizons and markers from over 200 wells, and available well logs covering the depth range from surface to the Carboniferous source rock (Romijn 2017; Dost et al. 2017). A gridded version $(50 \times 50 \times 25 \mathrm{~m})$ of the elastic model was created covering an area of $37.5 \times 40 \mathrm{~km}$ and a depth range of $5 \mathrm{~km}$. A representative 1D velocity model was constructed based on the 3D model, extrapolating beyond its limits to cover offsets up to $50 \mathrm{~km}$ (Fig. 1, right).

When simulating larger magnitude earthquakes the source function needs to be scaled up from a single point-source in order to account for finite fault effects. In its simplest form this can be defined by a uniform discretization of the fault into a grid of point sources scaled to the appropriate magnitude. The variables that need to be defined in this simple case are size of fault, rupture velocity, grid size and moment released at each grid point. The strike, dip and rake are defined by the general fault geometry, mechanism (pure-normal) and observed moment release in the field (strike: $270^{\circ}$, dip: $70^{\circ}$ and rake: $90^{\circ}$ ). To calculate the size of a rectangular rupture, with width $(W)$ and length $(L)$, we use the following relationship for normal faults:

$$
W^{2} L=\frac{8}{3 \pi} \frac{M_{0}}{\Delta \sigma},
$$

where $\Delta \sigma$ is the static stress drop. The uniform finite fault is discretized with the grid spacing determined by the quarter wavelength of the maximum frequency that we wish to preserve at the rupture velocity. The time delay between point sources is determined by rupture velocity and grid spacing. A rupture velocity of $0.8 \beta$ is used (Broberg 1996), where $\beta$ is the shear-wave velocity representative of the source vicinity.

It is well understood that fault ruptures are not uniform in nature (Mai and Thingbaijam 2014). As an extension to the finite-fault source model, a non-uniform slip model is used to observe the effects of the source model on simulated ground motions at the surface.

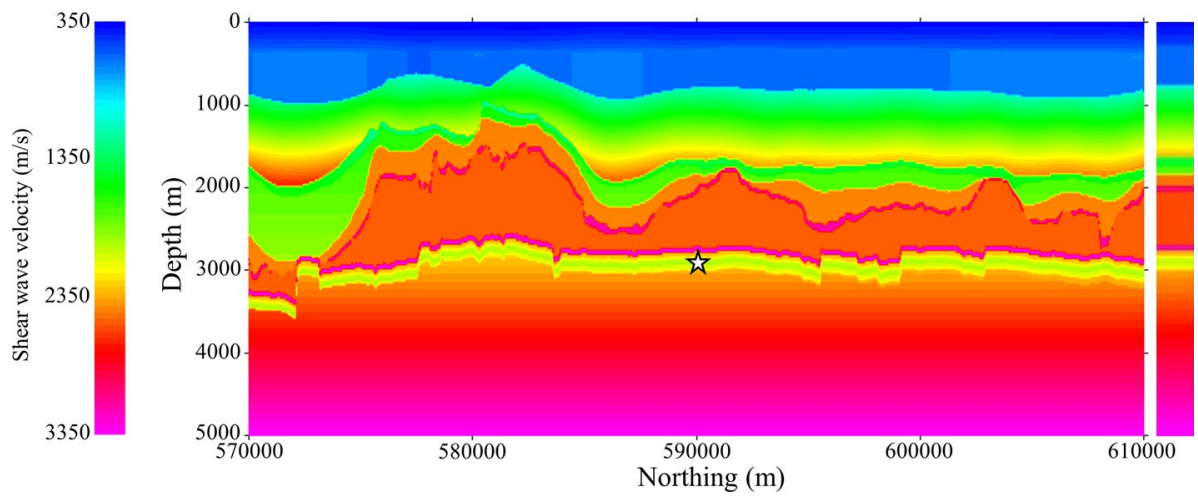

Fig. 1 South-north cross-section through the Groningen velocity model. The source location in the middle of the Groningen model is displayed as a star. The 1D representation of the 3D model is shown to the right. Note the vertical exaggeration. Near-surface velocities not well resolved (Kruiver et al. 2017) 
Understanding how heterogeneity dynamically evolves in Groningen is outside the scope of this study, therefore no a priori knowledge of rupture variability is assumed. Heterogeneity is imposed following the stochastic kinematic modelling approach outlined by Graves and Pitarka (2016) (Fig. 2). The implementation can be summarized as follows: (1) the slip distribution is determined such that the spectral decay of the distribution follows the von Karman correlation function with stochastic heterogeneity; (2) a local rupture velocity and slip initiation time is then determined based on the local slip distribution and additional stochastic heterogeneity; (3) each fault patch follows the kinematic slip rate function (Liu et al. 2006) with a rise time that is a function of the local slip distribution and additional stochastic heterogeneity; (4) the slip direction (rake) also follows the same spectral decay characteristics as the slip distribution but uses a different stochastic realization.

\subsection{Stochastic waveform modelling}

The simulation of earthquake ground motion time-histories using the stochastic method (Boore 2009) has been applied to various regions of weak-to-moderate seismicity. The method has been shown by Douglas et al (2013) to be suitable for application to induced earthquakes in a variety of contexts (e.g. natural and anthropogenic geothermal seismicity), while Atkinson (2015) showed that an empirically derived GMPE for induced earthquakes produced similar predictions to a stochastic simulation model developed for eastern North America. The stochastic method relies on the calibration of seismological models for the

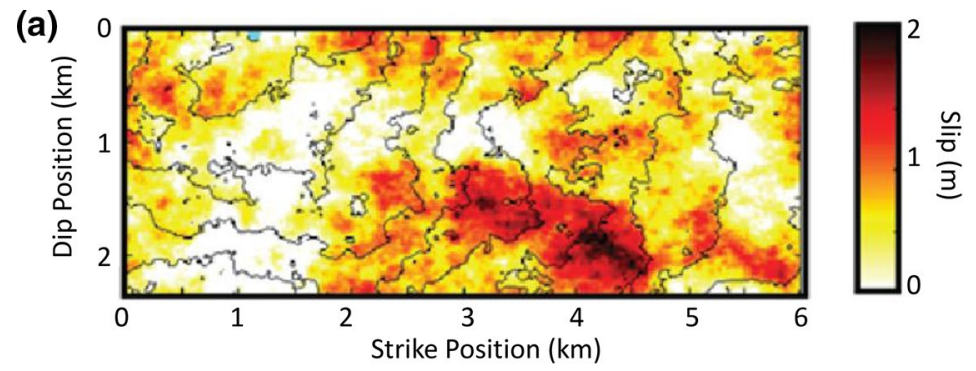

(b)
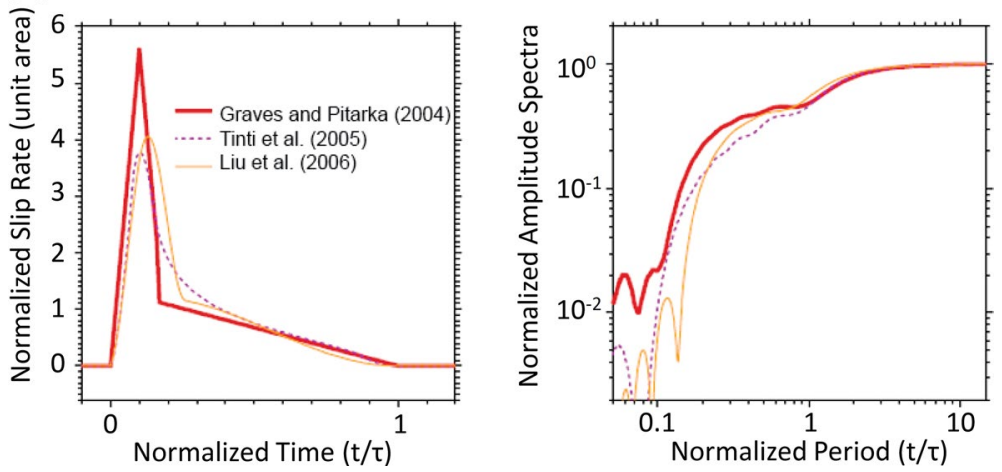

Fig. 2 Representation of kinematic fault rupture model for a M5.5 earthquake as outlined by Graves and Pitarka (2016). a An example rupture model showing the amount of slip (colour) and the variability in timing of rupture (contours) across the fault surface. b Different models of rise time can be used at each fault point. The model of Liu et al. (2006) is used here 
source function and path effects using high quality recordings of weak-motion data. The stochastic approach, and derivatives such as the hybrid-empirical method (Campbell 2003), have been widely used in engineering applications such as Senior Seismic Hazard Analysis Committee (SSHAC) probabilistic seismic hazard analyses (Bommer et al. 2015) and national seismic hazard assessments (Delavaud et al. 2012).

Waveforms used to develop the Groningen GMM are calculated using a finite-fault stochastic simulation methodology (EXSIM_dmb, version: 17/10/2016; Boore 2009), based on EXSIM (Motazedian and Atkinson 2005). Similar to the point source stochastic simulation technique used in earlier versions of the GMM (Bommer et al. 2017a), this approach produces broadband waveforms (and corresponding spectral ordinates) by defining a seismological model (earthquake source, propagation and site effects) and uses this to generate frequency-modulated, random phase acceleration time-histories. An advantage of this approach is that specific wave-propagation behaviour, controlled by the geological structure of the Groningen field, is accounted for by using recordings of small events $(\mathbf{M} \leq 3.5)$ to produce models describing path effects appropriate for point sources. The transition from these point sources (sub-faults) to finite-fault events is then controlled by the specific reservoir characteristics (primarily shear-wave velocity structure), in addition to the respective boundary conditions and slip assumptions used to generate fault ruptures.

For the simulations we use $75^{\circ}$ dip normal faulting, with rupture dimensions, $L \times W$, given by Wells and Coppersmith (1994) for $\mathbf{M} \geq 5$, or the Brune (1970) model for $\mathbf{M}<5$. Variability in fault size is accommodated through a zero-mean log-normal distribution with standard deviation 0.15 (natural log units). Fault length and width are negatively correlated to ensure that the total fault area $(L \times W)$ is maintained: we account for epistemic uncertainty (see Sect. 3.3) in the stress drop alone for simplicity but could equivalently vary fault area and stress drop with appropriate covariance. All hypocentres are located in the reservoir, at a depth of $3 \mathrm{~km}$, but occur randomly along strike. Ruptures grow downwards (such that the depth to rupture, $\left.Z_{\mathrm{TOR}}=3 \mathrm{~km}\right)$, limited by the seismogenic depth $(13 \mathrm{~km})$. Simulated ruptures that reach the maximum accommodated width are adjusted in length (ensuring, as before, that the rupture area is maintained). For events with $\mathbf{M} \leq 4$ slip velocity is $0.8 \times 2.0 \mathrm{~km} / \mathrm{s}$ (i.e. $80 \%$ of the reservoir's shear-wave velocity). For events with $\mathbf{M} \geq 5.5$, $0.8 \times 3.5 \mathrm{~km} / \mathrm{s}$ (i.e. $80 \%$ of the underlying Carboniferous' shear-wave velocity), with linear interpolation in the range $4.5<\mathbf{M}<5.5$.

An empirical significant duration model, based on the accumulation of 5-75\% of total Arias intensity $\left(T_{5,75}\right)$ and developed for Groningen (Bommer et al. 2017b), is used to define the shaking duration of individual sub-fault waveforms: $T_{\text {path }}=T_{5,75}\left(R, \mathbf{M}=3, V_{s 30}=1500 \mathrm{~m} / \mathrm{s}\right) / 0.383\left(\mathrm{R}^{2}=0.98\right)$. The sub-fault duration model $\left(T_{\text {path }}\right)$ has been calibrated to observed significant durations $\left(T_{5,75}\right)$ for an $\mathbf{M} 3$ event (equivalent to a single sub-fault) in the Groningen field (adjusted to the reference rock at which simulations are made, with travel-time averaged shear-wave velocity in the upper $30 \mathrm{~m}$, $V_{s 30}=1500 \mathrm{~m} / \mathrm{s}$ ). Individual sub-fault waveforms are subsequently summed, with appropriate time delay, to provide the waveform recorded at the reference horizon. The model therefore provides measured durations $\left(T_{5,75}\right)$ for low-magnitude events consistent with local seismicity, while scaling durations for finite faults according to their geometry and the velocity of the subsurface.

As discussed in Bommer et al. (2017b) inversions of Fourier spectra of recorded events (Fig. 3) are performed using a Bayesian approach with priors for (1) site amplification based on field-specific soil profiles, (2) stress drop, (3) the form of geometrical decay shown in the full-waveform simulations. These inversions yielded a range of event-, path- and site-specific parameters that are considered candidate sub-fault seismological models (Fig. 4). In order to 

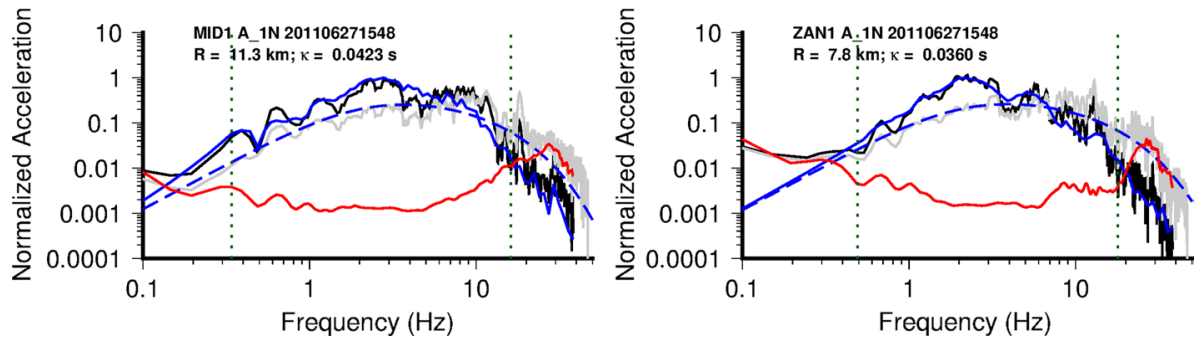

Fig. 3 Comparison of observed (surface recordings at MID1 and ZAN1 accelerometers) and modeled Fourier Amplitude Spectrum (FAS) for the $\mathbf{M}=3.2$ Garrelsweer event (27th June 2011). Black: surface acceleration FAS; red: surface noise FAS; grey: FAS deconvolved to reference rock using site transfer function; blue: modelled FAS (dashed: at reference horizon; and solid: at surface)

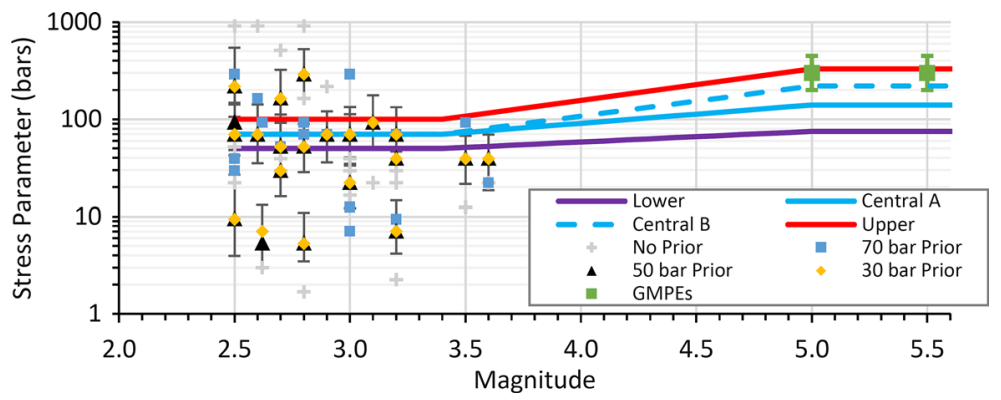

Fig. 4 Best fitting event-specific $\Delta \sigma$ for Groningen earthquakes using no prior, and 30, 50 and 70 bar priors, along with the models (lower, central $\mathrm{a} / \mathrm{b}$ and upper) used in the V5 GMM. Error bars $( \pm 5 \%$ misfit tolerance) are shown for the 50 bar prior results and indicative for the range of models suitable for global GMPEs

find GMM representative parameter sets for the stress parameter, $\Delta \sigma$, and site-specific attenuation, $\kappa_{0}$, simulations were compared to (1) Groningen response spectra at the at 20 spectral periods for which recorded data were available (0.01-2.5 s); and (2) pseudo spectral acceleration (PSA) at 6 spectral periods (PGA, 0.1, 0.2, 0.3, 1 and $2 \mathrm{~s}$ ) at magnitudes $\mathbf{M}=5,6$ and 7, for logarithmically spaced distances of $0,2.5,5,10$ and $20 \mathrm{~km}$ and with $\mathrm{V}_{\mathrm{S} 30}=1500 \mathrm{~m} / \mathrm{s}$ (the reference rock velocity). Six GMPEs were used as the target for these large magnitude cases: three NGA-W2 models (Boore et al. 2014; Chiou and Youngs 2014; Campbell and Bozorgnia 2014) in addition to the eastern North America model (Yenier and Atkinson 2015) and two European (RESORCE) models (Akkar et al. 2014; Bindi et al. 2014).

To assess the fit of candidate models inter-event terms are calculated at each oscillator period following Abrahamson and Youngs (1992). From the inter-event terms, $\eta$, the average model bias over all events, $b(T)$, is calculated. The average modulus bias, $\overline{|b|}$, over all $K$ periods ( $K=20$ for Groningen data, $K=6$ for the GMPEs) is then defined as:

$$
\overline{|b|},=\frac{1}{K} \sum_{k=1}^{K}\left|b\left(T_{k}\right)\right|
$$

and standard deviation, $\sigma_{|b|}$, of the period-to-period $\left|b\left(T_{k}\right)\right|$ as: 


$$
\sigma_{|b|}=\sqrt{\frac{1}{(K-1)} \sum_{k=1}^{K}\left(\left|b\left(T_{k}\right)\right|-\overline{|b|}\right)^{2}} .
$$

$\overline{|b|}$ and $\sigma_{|b|}$ provide a simulation specific (period-independent) measure of candidate GMM bias and period-to-period variability. The best fitting model for the recorded motions at the reference rock horizon was: $\Delta \sigma=70$ bar; $\kappa_{0}=0.010 \mathrm{~s}(\overline{|b|}=0.058 \pm 0.087$ over the 20 periods). This event-independent $\Delta \sigma$ is consistent with the average value determined through spectral analysis (Fig. 4). On the other hand, simulation models consistent with the GMPE predictions were best-fit using higher values of $\Delta \sigma: 200-400$ bars.

\section{Results and synthesis of simulations for Groningen}

\subsection{Point source simulations}

The main objective of the point-source finite-difference modelling was to determine elastic wave-propagation behaviour to constrain the GMM path characteristics in respect to Groningen geology. To achieve this and capture the impacts and sensitivities of our assumptions, various simulations were conducted. For each simulation we have varied the source mechanism (strike angles from $130^{\circ}$ to $170^{\circ}$ and $310^{\circ}$ to $350^{\circ}$, dip angles from $60^{\circ}$ to $90^{\circ}$ and rake angles from $-100^{\circ}$ to $-80^{\circ}$ ), earthquake locations and source time function (source corner frequencies).

In Fig. 5, the analysis of geometric mean PGV is illustrated for a source location in the middle of the Groningen field (at reservoir level). It can be observed that the amplitude decay with distance strongly deviates from the $R^{-1}$ behaviour that would be expected in a homogeneous medium: in the first $7 \mathrm{~km}$ the amplitudes decay at the highest rate $\sim R^{-2}$, followed by an inversion and an amplitude increase with distance from $\sim 7-12 \mathrm{~km}$, after which the amplitude decays with $\sim R^{-1}$. The bump at around $10 \mathrm{~km}$, visible at all azimuths for this particular source location, seems to be characteristic for the entire Groningen field and is therefore also present for alternative source locations and alternative source mechanisms. The exact form of the decay (i.e. decay rates) does change depending on scenario, however. The results of the analyses, including variability, are summarized in Table 1 . In general, the 1D velocity model leads to sharper features in terms of geometrical spreading: higher initial decay, followed by a stronger bump, assumed to be related to more coherent reflected phases. At distances beyond $12 \mathrm{~km}$, the decay in the $1 \mathrm{D}$ case is similar to a halfspace model, with $R^{-1.16}$, while the $3 \mathrm{D}$ model leads to stronger decay, although only up to $25 \mathrm{~km}$.

\subsection{From point to non-uniform finite-faults}

The motivation behind the finite-fault full-waveform simulations performed for this study was not only to determine the influence of the fault model at higher magnitudes, but how the influence of the source model scales with magnitude. Specifically, for Groningen where observations are limited to magnitudes less than M3.5 we wish to know how scalable simulations at low magnitude are to larger potentially damaging events. 

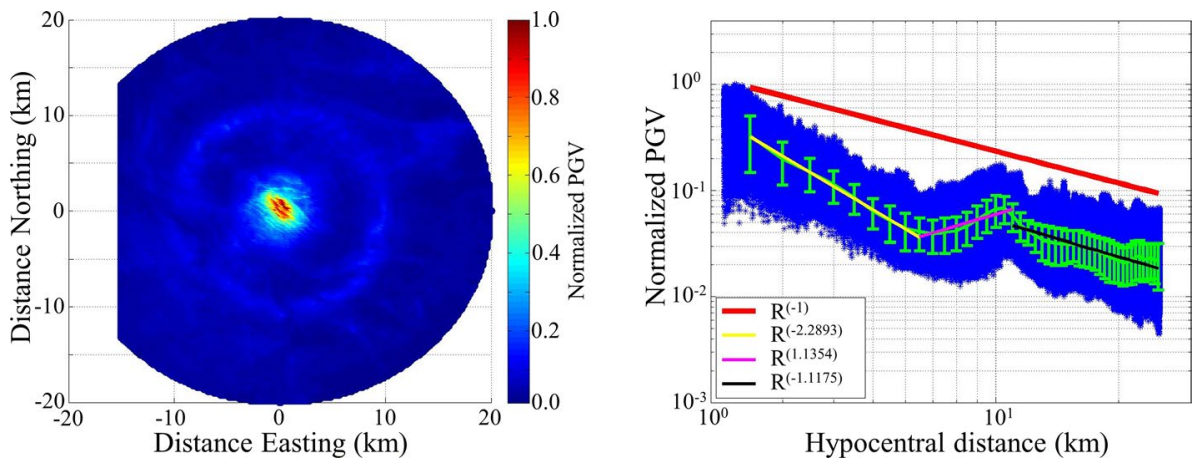

Fig. 5 Illustration of the PGV analysis based on full waveform simulations for a source in the reservoir in the middle of the Groningen field using a Brune source wavelet with corner frequency of $f_{0}=4 \mathrm{~Hz}$. Left: a map of derived PGV over all source mechanisms. Right: the PGV values of the map displayed as a function of hypocentral distance; the red line represents the expected geometrical spreading behaviour in a homogeneous medium

Table 1 Summary of geometrical spreading analysis using point-source elastic full waveform modelling

\begin{tabular}{llll}
\hline Simulation & Slope $2.5-7 \mathrm{~km}$ & Slope $7-12 \mathrm{~km}$ & Slope 12-[25/50] km \\
\hline 3D Groningen PGV & $-2.16 \pm 0.06$ & $0.9 \pm 0.12$ & $-1.4 \pm 0.03$ \\
1D Groningen PGV & -2.46 & 1.337 & -1.16 \\
\hline
\end{tabular}

In the last column, the distance segment ranges from 12 to $25 \mathrm{~km}$ for the $3 \mathrm{D}$ model and from 12 to $50 \mathrm{~km}$ for the $1 \mathrm{D}$ model. Variability in the decay rate is indicated for the $3 \mathrm{D}$ case

As shown in Fig. 6, for the lower magnitude events the waveform simulations produced a good fit to the observed peak ground and spectral accelerations. However, of more interest is the influence the source model has on simulated ground motions as magnitude increases. Using waveform simulations, the sensitivity of the simulated ground motions to increasingly complex source models is therefore tested. Of particular interest is how source representations' impact on ground motions scales with magnitude and distance to the rupture. In Fig. 7, simulated ground motions at the reference rock horizon for M3 and M6 events are shown. For these simulations the source is modelled as (1) a point, (2) a uniform finite fault and (3) a non-uniform finite fault, all with identical strike, dip and rake. The finite source is $0.2 \times 0.2 \mathrm{~km}$ for a magnitude M3 and $7 \times 7 \mathrm{~km}$ for the M6. For the M3 the impact of the finite fault over a simple point source representation is mostly diminished by the time the wavelet reaches the surface. On the other hand, the M6 source produces significantly different ground motions in the near field $\left(\mathrm{R}_{\text {rup }}<10 \mathrm{~km}\right)$ depending on whether a point, uniform or nonuniform finite-fault source is used.

Figure 8 shows PGA maps over the bedrock horizon for three different fault representations for a M6 event with the same source mechanism. The point source isolates energy in the near field, in contrast to the finite fault representations, and is most sensitive to $3 \mathrm{D}$ velocity structure. At the other end of the spectrum, the non-uniform finite fault shows little deviation from a linear exponential trend in its decay in ground 

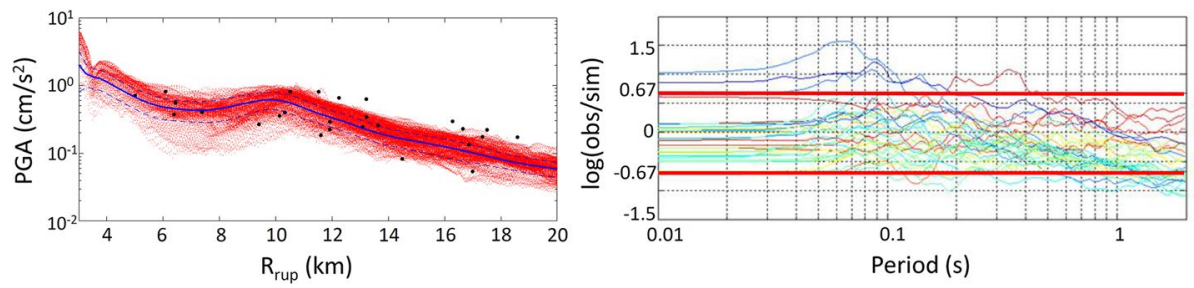

Fig. 6 Comparison of (left) peak ground acceleration and (right) spectral acceleration for wavefield simulations and observations for the M3.1 30th September 2015 event near the town of Hellum. The simulations are calculated at the rock reference, while the observations are made at $200 \mathrm{~m}$ geophones for peak acceleration, and the surface accelerometer for the spectral accelerations. \pm 0.67 red lines are shown to indicate the cut off for SCEC validation
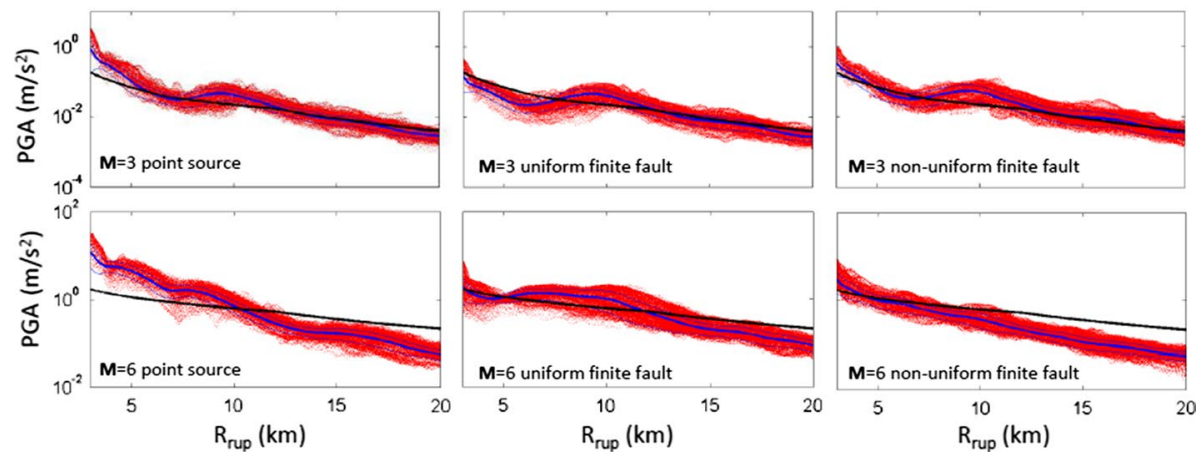

Fig. 7 Comparison of the effect of source model type on ground motions for an M3 and M6 event. PGA versus rupture distance is shown for a point source (left), uniform finite fault (middle) and non-uniform (right) finite fault. Red dots indicate individual simulated PGA values, the blue lines show the median and standard deviation of simulated PGA, and the black line shows the Groningen GMM

accelerations which can be contributed to a more complex wave-field and more broadly dispersing energy.

\subsection{The Groningen ground motion model}

Online Resource 1 summarises the full set of inputs to the finite-fault stochastic simulations used to generate the motions at the reference rock for the Groningen GMM. This includes the path model informed by point source finite-difference modelling using both $1 \mathrm{D}$ and 3D velocity models (Fig. 5, Table 1). An important constraint was that the model must be consistent with recorded data from the field over a range of magnitude $(2.5 \leq \mathbf{M} \leq 3.5)$ and distance $\left(0 \leq \mathrm{R}_{\text {epi }} \leq 60 \mathrm{~km}\right)$. This prevented direct use of either the $1 \mathrm{D}$ or $3 \mathrm{D}$ simulation-based models, which are location and scenario dependent and do not, on average, provide unbiased residuals for all recorded events. Further regression of the empirical data was performed, using the geometrical spreading models from finitedifference simulations as a starting point and determining the minimum (least squares) misfit. The final model uses decay rates of $-1.55,-0.23,-1.43,-1.00$ at distances up to $7 \mathrm{~km}$, between 7 and $12 \mathrm{~km}, 12$ and $25 \mathrm{~km}$ and beyond $25 \mathrm{~km}$, respectively. The 


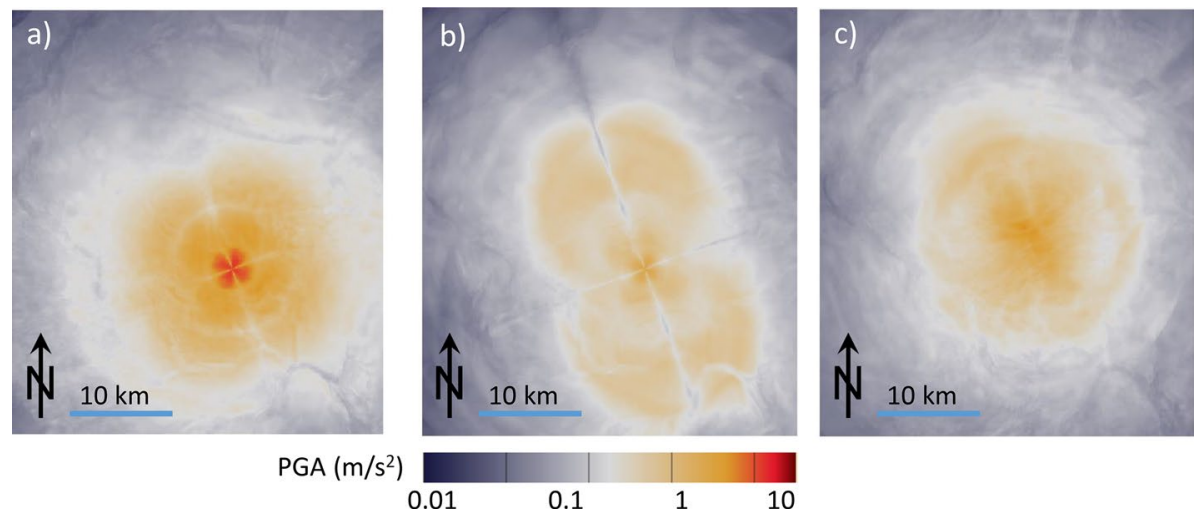

Fig. 8 Geometric mean of peak ground acceleration measured on a simulated bedrock surface for three different source representations: a point source, $\mathbf{b}$ uniform finite fault and $\mathbf{c}$ non-uniform finite fault. Measurements are made on a grid every $25 \mathrm{~m}$, simulations are finite difference elastic, with post-processing $\mathrm{Q}$ filter applied and use the Groningen model $\left(V_{P}, V_{S}\right.$ and density, Fig. 1) for path effects

latter two segments are very similar to the decay observed in the simulation models (3D for the 12-25 km segment and 1D for beyond $25 \mathrm{~km}$ ). The initial rate of decay (in the first two segments) is lower than observed in the finite-difference simulations, with less severe bump between 7 and $12 \mathrm{~km}$, although the general shape and break points are the same.

For the simulations it was decided to use alternative values of $\Delta \sigma$ to reflect the considerable epistemic uncertainty associated with extrapolation to much larger magnitudes. In the magnitude range covered by data $(\mathbf{M} \leq 3.5)$ the two central GMM branches have a $\Delta \sigma=70$ bars (minimum bias to recorded data), the lower branch 50 bars (GMM bias $\sim-0.5 \tau$ to $-\tau$, where $\tau$ is the inter-event standard deviation of the event-terms) andreflecting the possibility of the motions being similar to those from normal tectonic earthquakes - the upper branch has $\Delta \sigma=100$ bars (GMM bias $\sim+0.5 \tau$ to $+\tau$ ). All models exhibit an increase of stress parameter with magnitude, reflecting the belief that for larger events, increasingly sampling greater depths of the crust, the low $\Delta \sigma$ values observed in the reservoir at low $\mathbf{M}$ are unrealistic. For the two central models $(a / b), \Delta \sigma$ rises to 140 bars and 220 bars at M5, respectively, then remains constant. Similarly, the lower and upper models rise to 75 bars and 330 bars, respectively. The latter is designed to produce motions, given the Groningen-specific attenuation and site characteristics, that are similar to those observed globally. The lower model, with stress drops increasing to 75 bars for $\mathbf{M} \geq 5$, is designed to reflect the fact that we do not believe that median stress drops at moderate and large magnitude could be lower than those observed for local seismicity in the reservoir. The overall spread of the models is designed to be consistent-increasing by a factor of $\sim 1.5$ for each branch, apart from the lowermost branch-where 75 bars is chosen as the upper level for the lower model, consistent with a 'self-similar' magnitude scaling (i.e. consistent with the central models at low magnitude).

For each of the GMM branches (lower, central $a / b$, and upper), response spectra were simulated using EXSIM_dmb for 2100 scenario events with $\mathbf{M}=2.0$ to 7.0 in steps of 0.25 . For each scenario event a random epsilon was selected to define the length and width of the rupture. Recording locations were placed radially above the centre of the fault's top edge at $0 \mathrm{~km}$ and then 25 distances logarithmically spaced between 1.0 and $79.5 \mathrm{~km}$. For 

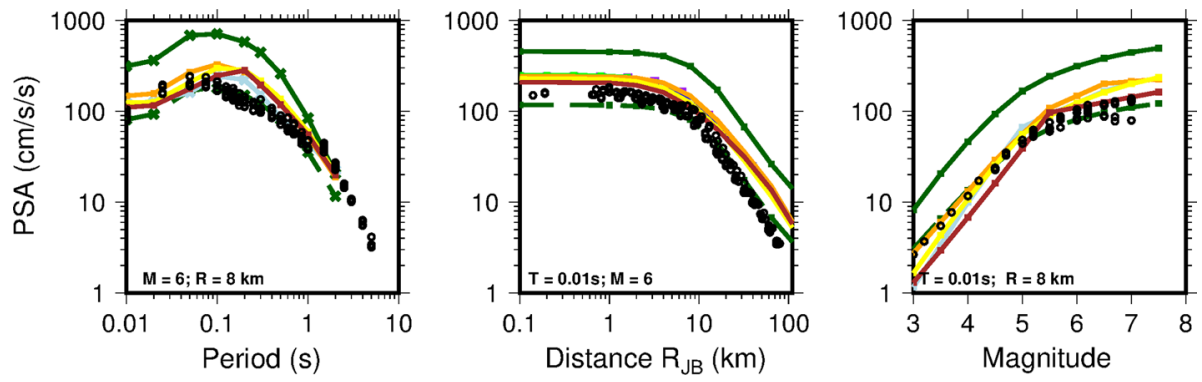

Fig. 9 EXSIM simulations (circles) for the central-a GMM compared against several GMPEs. Scenarios are indicated in the labels. Dark green: Yenier and Atkinson (2015) (dashed=3 km, solid=10 km hypocentre depth); yellow: Campbell and Bozorgnia (2014); orange: Chiou and Youngs (2014); purple: Akkar et al. (2014); light green: Bindi et al. (2014); brown: Boore et al. (2014); light-blue: Abrahamson et al. (2014) (note that this GMPE is not used in the calibration)
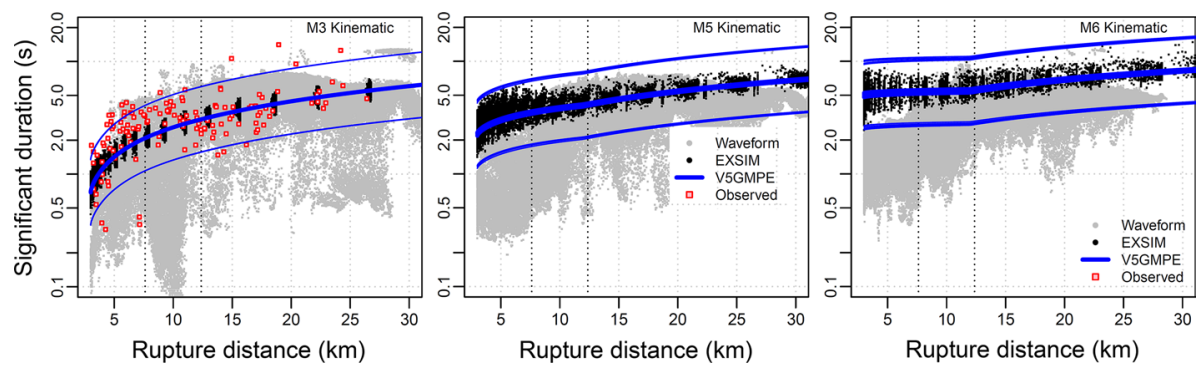

Fig. 10 Comparison of simulated 5-75\% significant durations. Estimates from numerical waveform modelling are shown using grey dots, stochastic simulations (EXSIM) are shown using black dots, observed durations for events with magnitudes in the range [2.8,3.2] are shown in the upper left panel, and blue lines show the V5 model predictions (median, \pm 1 standard deviation). Vertical dotted lines indicate locations where breaks in amplitude scaling have been identified

each distance 8 sites were located, at 0 to $315^{\circ}$ (in $45^{\circ}$ steps). In total 1.75 million response spectra were calculated, or 436,800 for each of the model branches. Figure 9 shows the simulated data using the central- $a$ GMM seismological model for a single M6.0 event. The simulations for each branch were then regressed to provide four equations as detailed in Bommer et al. (2017b).

Significant duration, representing the duration over which $5-75 \%$ of the total Arias intensity is accumulated, is important for the Groningen hazard and risk calculations (Crowley et al. 2017). Figure 10 shows a comparison of observed and computed durations for a number of scenarios, with site response corrections for the various references based on Afshari and Stewart (2016a). For the M3 scenario it is possible to make a comparison with duration measures from real records. These observed durations are used to constrain the aleatory variability in the V5 duration model, represented by the thin blue lines in the panels.

While the finite-difference waveform modelling results show a far larger spread of duration values than the stochastic simulations, it is important to note that sub-fault duration variability is not incorporated within the EXSIM simulations. The stochastic simulations therefore provide a reasonable estimate of the median levels of duration (which are their purpose in this context), but the aleatory variability is constrained outside of the simulation 
process. In contrast, the durations from the full waveform modelling span a large range of durations, but it is notable that some of the apparent outliers among the observed durations are consistent with the simulation extrema. Such comparisons cannot be made for the larger considered scenarios because no empirical data is available from the field for these magnitudes. However, the larger scenarios indicate that the finite-difference modelling predictions of the duration are systematically lower than estimates from EXSIM. Afshari and Stewart (2016b) found that EXSIM tends to over-predict natural durations by about $25 \%$, which would bring the predictions closer. At short distances, however, the finite-difference full waveform estimates are significantly below those from EXSIM and appear inconsistent with expectations from natural events of the same magnitude. Finally, we note that relatively low estimates of duration occur in the distance ranges where significant changes in path scaling of ground motion amplitudes have been observed. This is consistent with a conceptual model in which multiple waves arrive in a short temporal window, leading to short durations and high amplitudes (Bommer et al. 2016).

\section{Discussion and conclusion}

The Groningen GMM has benefitted from a variety of full-waveform simulation techniques that have been employed to investigate wave-propagation in the Groningen gas field. The GMM in its current form (V5) is based on finite-fault stochastic simulations, which utilise recordings of small-events to define propagation effects from source to reference rock. The model describing the source-, path- and site-effects has been developed through inversion of weak motion data and considerations of epistemic uncertainty, both of which have been guided by finite-difference simulations concurrent to the GMM development.

The main contributions of the finite difference full-waveform simulations to the development of the Groningen GMM are two-fold: firstly, the elastic point-source simulations have been used to develop the form of the geometrical decay function. While we were not able to directly use the decay rates determined using full-waveform simulations (due to their strong dependence on the heterogeneity of the subsurface, and relative location of source and site), the stable model form (defined hinge points separating regimes of decay) was a crucial constraint. We believe that the particular shape of the spreading function could be caused by several factors, such as seismic energy propagating downwards into the Carboniferous and turning back to the surface at larger distances, as well as the interference of multiple wave types. Secondly it has been verified through finite-difference full-waveform simulations, that the persistence of the strong localised reflections (at $\sim 7-10 \mathrm{~km}$ ) is weakened for larger events, particularly for non-uniform faults.

It is worth noting that, in contrast to the behavior observed in real data, a frequency dependence of the apparent geometrical decay was apparent in finite-difference simulations. The bump in the distance-amplitude function (Figs. 5 and 7) only being apparent at moderate and high frequencies ( $\mathrm{f}>\sim 2 \mathrm{~Hz}$ ) and most pronounced at $\sim 10 \mathrm{~Hz}$ in the 1D model. This should therefore be viewed with caution and requires further investigation. One possible reason may be the over-emphasis of 1D structures and sharp boundaries in 3D models that do not exist in practice, as evidenced by the reduction in frequency dependence from 1D to 3D.

The durations produced through finite-fault simulations showed consistency between difference methods up to M5-although finite difference full waveform simulations generally have more variability, particularly extending to low durations. EXSIM simulations 
have been shown previously to overestimate durations by $\sim 25 \%$ which may account for some differences. Tests showed that the finite difference simulation are highly dependent on path effects and the velocity model used: the $3 \mathrm{D}$ velocity model is well-calibrated as a time-to-depth model but is not necessarily well-suited for generating strong internal multiples and scattering.

Another application of the finite-fault simulations has been in exploring the spatial correlation of ground motions in the Groningen field, which is discussed by Stafford et al. (2018). The ability of the waveform simulations to resolve field-specific path effects, and to scale these to magnitudes beyond which empirical data exist, provides a powerful tool to identify random and systematic components of spatial variations in ground-motion fields. The finite-difference simulations will therefore play a critical role in enabling the end goal of a fully non-ergodic GMM to be realised.

Investigation of wave-propagation effects from point-source through to non-uniform finite-fault ruptures has provided valuable insights into the resulting ground motion fields. It is clear from these analyses that simple adjustment of existing GMPEs would be insufficient to account for the complex features observed. We believe that finite-fault stochastic simulations-guided by full waveform simulations such as the finite-difference method used here-currently provide the best balance between providing a unique location-specific prediction of wave-field effects (and their scaling to finite ruptures), and the robustness afforded by empirical models. In the next generation of fully path-specific non-ergodic ground motion models, full waveform simulations will clearly be a key component.

Acknowledgements This work was initiated and funded by Nederlandse Aardolie Maatschappij B.V. (NAM). Numerous individuals have contributed to workshops, discussions and exchanges organised by NAM on the topic of ground motion simulation in the Groningen gas field to whom we thank. In particular we wish to thank participants (Norm Abrahamson, Luis Angel Dalguer, Christine Goulet and Bob Youngs) who provided valuable insights, suggestions and feedback during a NAM-organised workshop on finitefault simulations in London in July 2016. We also wish to express particular gratitude to the members of an international panel of experts who provided valuable review, including feedback, suggestions, criticisms and endorsement throughout the Groningen ground motion model development: Jonathan Stewart, Norm Abrahamson, Gail Atkinson, Hilmar Bungum, Fabrice Cotton, John Douglas, Jonathan Stewart, Ivan Wong and Bob Youngs. We finally extend our thanks to three anonymous reviewers and the editors for their positive and helpful comments.

Open Access This article is distributed under the terms of the Creative Commons Attribution 4.0 International License (http://creativecommons.org/licenses/by/4.0/), which permits unrestricted use, distribution, and reproduction in any medium, provided you give appropriate credit to the original author(s) and the source, provide a link to the Creative Commons license, and indicate if changes were made.

\section{References}

Abrahamson NA, Youngs RR (1992) A stable algorithm for regression-analyses using the random effects model. Bull Seismol Soc Am 82:505-510

Abrahamson NA, Silva WJ, Kamai R (2014) Summary of the ASK14 ground motion relation for active crustal regions. Earthq Spectra 30:1025-1055

Afshari K, Stewart JP (2016a) Physically parameterized prediction equations for significant duration in active crustal regions. Earthq Spectra 32:2057-2081

Afshari K, Stewart JP (2016b) Validation of duration parameters from SCEC broadband platform simulated ground motions. Seismol Res Lett 87:1355-1362

Aki K, Richards PG (1980) Quantitative seismology: theory and methods. W. H. Freeman, San Francisco

Akkar S, Sandikkaya MA, Bommer JJ (2014) Empirical ground-motion models for point- and extendedsource crustal earthquake scenarios in Europe and the Middle East. Bull Earthq Eng 12:359-387 
Atkinson GM (2015) Ground-motion prediction equation for small-to-moderate events at short hypocentral distances, with application to induced-seismicity hazards. Bull Seismol Soc Am 105:981-992

Bahrampouri M, Rodriguez-Marek A, Bommer JJ (2018) Mapping the uncertainty in modulus reduction and damping curves into the uncertainty of site amplification factors. Soil Dyn Earthq Eng. https://doi. org/10.1016/j.soildyn.2018.02.022

Bindi D, Massa M, Luzi L et al (2014) Pan-European ground-motion prediction equations for the average horizontal component of PGA, PGV, and 5\%-damped PSA at spectral periods up to $3.0 \mathrm{~s}$ using the RESORCE dataset. Bull Earthq Eng 12:391-430

Bommer JJ, Coppersmith KJ, Coppersmith RT et al (2015) A SSHAC level 3 probabilistic seismic hazard analysis for a new-build nuclear site in South Africa. Earthq Spectra 31:661-698

Bommer JJ, Dost B, Edwards B, Stafford PJ, van Elk J, Doornhof D, Ntinalexis M (2016) Developing an application-specific ground-motion model for induced seismicity. Bull Seismol Soc Am 106:158-173

Bommer JJ, Dost B, Edwards B et al (2017a) Developing a model for the prediction of ground motions due to earthquakes in the Groningen gas field. Neth J Geosci 96:s203-s213

Bommer JJ, Stafford PJ, Edwards B, Dost B, van Dedem E et al (2017b) Framework for a ground-motion model for induced seismic hazard and risk analysis in the Groningen gas field, the Netherlands. Earthq Spectra 33:481-498

Boore DM (2009) Comparing stochastic point-source and finite-source ground-motion simulations: SMSIM and EXSIM. Bull Seismol Soc Am 99:3202-3216

Boore DM, Stewart JP, Seyhan E, Atkinson GM (2014) NGA-West2 equations for predicting PGA, PGV, and 5\% damped PSA for shallow crustal earthquakes. Earthq Spectra 30:1057-1085

Bourne S, Oates S, Bommer J, Dost B, van Elk J, Doornhof D (2015) A Monte Carlo method for probabilistic hazard assessment of induced seismicity due to conventional natural gas production. Bull Seismol Soc Am 105:1721-1738

Broberg K (1996) How fast can a crack go? Mater Sci 32:80-86

Brune JN (1970) Tectonic stress and spectra of seismic shear waves from earthquakes. J Geophys Res 75:4997-5009

Campbell KW (2003) Prediction of strong ground motion using the hybrid empirical method and its use in the development of ground-motion (attenuation) relations in eastern North America. Bull Seismol Soc Am 93:1012-1033

Campbell KW, Bozorgnia Y (2014) NGA-West2 ground motion model for the average horizontal components of PGA, PGV, and 5\% damped linear acceleration response spectra. Earthq Spectra 30:1087-1115

Chiou BS-J, Youngs RR (2014) Update of the Chiou and Youngs NGA model for the average horizontal component of peak ground motion and response spectra. Earthq Spectra 30:1117-1153

Crowley H, Polidoro B, Pinho R, van Elk J (2017) Framework for developing fragility and consequence models for local personal risk. Earthq Spectra 33:1325-1345

Delavaud E, Cotton F, Akkar S et al (2012) Toward a ground-motion logic tree for probabilistic seismic hazard assessment in Europe. J Seismol 16:451-473

Dost B, Van Eck T, Haak H (2004) Scaling of peak ground acceleration and peak ground velocity recorded in the Netherlands. Boll Geofis Teor Appl 45:153-168

Dost B, Ruigrok E, Spetzler J (2017) Development of seismicity and probabilistic hazard assessment for the Groningen gas field. Neth J Geosci 96:s235-s245

Dost B, Edwards B, Bommer JJ (2018) The relationship between $\mathbf{M}$ and $\mathrm{M}_{\mathrm{L}}$ : a review and application to induced seismicity in the Groningen gas field, The Netherlands. Seismol Res Lett. https://doi. org $/ 10.1785 / 02201700247$

Douglas J, Edwards B, Convertito V, Sharma N, Tramelli A, Kraaijpoel D, Cabrera BM, Maercklin N, Troise C (2013) Predicting ground motion from induced earthquakes in geothermal areas. Bull Seismol Soc Am 103:1875-1897

Graves R, Pitarka A (2016) Kinematic ground motion simulations on rough faults including effects of 3D stochastic velocity perturbations. Bull Seismol Soc Am 106:2136-2153

Kraaijpoel D, Dost B (2013) Implications of salt-related propagation and mode conversion effects on the analysis of induced seismicity. J Seismol 17:95-107

Kruiver PP, van Dedem E, Romijn R et al (2017) An integrated shear-wave velocity model for the Groningen gas field, The Netherlands. Bull Earthq Eng 15:3555-3580

Liu P, Archuleta RJ, Hartzell SH (2006) Prediction of broadband ground-motion time histories: hybrid low/high-frequency method with correlated random source parameters. Bull Seismol Soc Am 96:2118-2130

Madariaga R (2007) Seismic source theory. Elsevier, Amsterdam 
Mai PM, Thingbaijam K (2014) SRCMOD: an online database of finite-fault rupture models. Seismol Res Lett 85:1348-1357

Motazedian D, Atkinson GM (2005) Stochastic finite-fault modeling based on a dynamic corner frequency. Bull Seismol Soc Am 95:995-1010

Mulder WA, Plessix R-E (2002) Time- versus frequency-domain modelling of seismic wave propagation, Abstract E015, 64th EAGE, Florence, May 27-30, 2002

Noorlandt R, Kruiver PP, de Kleine MP et al (2018) Characterisation of ground motion recording stations in the Groningen gas field. J Seismol. https://doi.org/10.1007/s10950-017-9725-6

Rodriguez-Marek A, Kruiver PP, Meijers P et al (2017) A regional site-response model for the Groningen gas field. Bull Seismol Soc Am 107:2067-2077

Romijn R (2017) Groningen velocity model 2017-Groningen full elastic velocity model September 2017, in NAM technical report. Available www.nam.nl/feiten-en-cijfers/onderzoeksrapporten. Accessed Mar 2018

Spetzler J, Dost B (2017) Hypocentre estimation of induced earthquakes in Groningen. Geophys J Int 209:453-465

Stafford PJ, Rodriguez-Marek A, Edwards B et al (2017) Scenario dependence of linear site effect factors for short-period response spectral ordinates. Bull Seismol Soc Am 107:2859-2872

Stafford PJ, Zurek BD, Ntinalexis M, Bommer JJ (2018) Extensions to the Groningen ground-motion model for seismic risk calculations: component-to-component variability and spatial correlation. Bull Earthq Eng. https://doi.org/10.1007/s10518-018-0425-6

van Elk J, Doornhof D, Bommer JJ et al (2017) Hazard and risk assessments for induced seismicity in Groningen. Neth J Geosci 96:s259-s269

Wells DL, Coppersmith KJ (1994) New empirical relationships among magnitude, rupture length, rupture width, rupture area, and surface displacement. Bull Seismol Soc Am 84:974-1002

Yenier E, Atkinson GM (2015) Regionally adjustable generic ground-motion prediction equation based on equivalent point-source simulations: application to central and eastern North America. Bull Seismol Soc Am 105:1989-2009

\section{Affiliations}

\section{B. Edwards ${ }^{1}$ (D) B. Zurek ${ }^{2} \cdot$ E. van Dedem ${ }^{3} \cdot$ P. J. Stafford ${ }^{4} \cdot$ S. Oates ${ }^{3} \cdot$ J. van Elk $^{5}$. B. deMartin ${ }^{2}$. J. J. Bommer ${ }^{4}$}

1 Department of Earth, Ocean and Ecological Sciences, University of Liverpool, Liverpool L69 3GP, UK

2 ExxonMobil Upstream Research Company, 22777 Springwoods Village Parkway, Spring, TX 77389, USA

3 Shell Global Solutions International B.V., P.O. Box 60, 2280 AB Rijswijk, The Netherlands

4 Department of Civil and Environmental Engineering, Imperial College London, London SW7 2AZ, UK

5 Nederlandse Aardolie Maatschappij B.V. (NAM), Schepersmaat 2, 9405 TA Assen, The Netherlands 